\title{
Study on the Suitability of Reclaimed Asphalt Pavement Aggregate (RAPA) in Hot Mix Asphalt Production
}

\section{DOI : 10.36909/jer.14605}

\author{
Tiruwork Mulatu*, Biruk Yigezu** and Anteneh Geremew*** \\ *, **, *** Jimma University, Faculty of Civil and Environmental Engineering, Jimma, Ethiopia \\ * Corresponding Author: tiruworkmule@gmail.com
}

\begin{abstract}
The main objective of this study was to evaluate the suitability of recycled asphalt aggregate with fresh aggregate in hot mix asphalt production by using experimental laboratory investigation. Also, Nonprobable sampling techniques were adopted to collect a sample. The engineering properties of extracted Reclaimed asphalt pavement aggregate and the fresh crushed aggregate were identified based on standard specification before starting the Marshall Mix design, Then the Marshall Stability test was conducted on crushed aggregate with three different aggregate gradation sizes $5.0 \%, 5.5 \%$ and $6.0 \%$ by weight of aggregates and with five different bitumen content $4.0 \%, 4.5 \%, 5.0 \%, 5.5 \%$ and $6.0 \%$ by weight of total mix. Depending on the selected aggregate gradation Marshall Stability test was conducted for reclaimed asphalt pavement aggregate with a replacement rate of 5.0\%, 15\%, 25\%,35\%, 45\%, 55\%, and 65\% by weight of crushed aggregate to determine its optimum bitumen content according to National Asphalt Pavement Association method (NAPAM). A total of 64 mix designs and 190 specimens were prepared. Hence, Marshall Stability and Moisture Susceptibility test with 3-trials, hence rutting test with 2-trials. From 190 specimens, 45 were for the control mix, 105 were for replacement proportion, 36 were for Moisture Susceptibility and 4 were for Rutting Based on the Marshall Test results and their performance tests such as Moisture Susceptibility and Rutting was performed to maximum allowable replacement percentage was compared with standard specification. The optimum bitumen content result obtained in percent was 5.1, 5.04, 4.98, 4.87, 4.81, 4.74, 4.67 and 4.53 for $0 \%$ (control), 5.0\%, 15\%, 25\%, 35\%, 45\%, $55 \%$ and $65 \%$, respectively. The experimental value of Tensile Strength Ratio, proportional rut depth and mean rut depth on $45 \%$ RAPA replacement was $85.42 \%$ and $4.48 \%, 2.24 \mathrm{~mm}$ respectively. Finally, the test result obtained from the marshal stability and the performance testes indicates that up to $45 \%$ replacement of aggregate is reclaimed asphalt pavement aggregate in hot mix asphalt production satisfies the standard specification.
\end{abstract}

Keywords: Reclaimed asphalt pavement; Marshall Test; Crushed aggregate; Proportional rut depth Tensile Strength Ratio; Percentage by weight.

\section{INTRODUCTION}

Roads are the broadest infrastructure to be constructed worldwide by providing door-to-door services to transport peoples and materials from one place to another at a reasonable cost compared to other transportation modes. The design and constituent materials used are classified into three major types: Rigid pavement, flexible pavement, and composite pavement. A rigid pavement is typically prepared by Portland cement concrete (PCC), an asphalt pavement is typically made of hot mix asphalt (HMA) while a composite pavement is composed of both. Composite pavements type is rarely used in construction for its initially high costs and complex analysis involved during the design stage (Pranav et al., 2020). 
The primary purpose of constructing a flexible pavement to transmit load coming from the upper layer of the surface to the subbase and underlying subgrade soil. These materials contain sand and gravel or crushed stone aggregate when compacted with a binder of bituminous material to make more plasticity property absorb stress, and a proper mix design is needed and adequately satisfies the standard specification(Gonfa et al., 2020; Schaefer et al., 2008). Many materials are required to design an asphalt mixture, but these resources are not easily available near the construction area and due to limited sources. Therefore to reduce this limitation, an alternative waste material to be substituted with virgin aggregate satisfies the standard specification suitable alternative material is Reclaimed Asphalt Pavement (RAP) (Geraldin \& Makmur, 2020; Hrůza et al., 2020; Pourtahmasb \& Karim, 2014).

The existing old asphalt pavement material may significantly value when the asphalt pavement even approaches its design life. Recognizing the importance of the existing aggregate and asphalt resources, agencies and contractors have prepared extensive use of RAP to produce new asphalt concrete pavements for a long time. RAP has been approved to be used construction materials due to its economic advantage and environmental benefits. Also, the scarcity in the accessibility of the virgin aggregates, quarrying operations restrictions makes it a necessity to include RCA's use in concrete pavements (Alwetaishi et al., 2019; Swiertz et al., 2011).

These materials are produced while asphalt concrete pavements are removed during reconstruction, resurfacing, or access to buried utilities. Once properly crushed and screened, RAP comprises highquality, well-graded aggregates coated by asphalt cement. Recycled asphalt aggregate materials adequately processed and blended with a conventional aggregate satisfies a performance of the granular road base longer than 20 years, and now it considered a standard practice in many countries, including in Ethiopia, recycled asphalt aggregate used as a capping layer and sub-base material in various construction projects. Either milling or full-depth removal generally removes asphalt pavement. Milling entails removing the pavement surface using a milling machine, removing up to $50 \mathrm{~mm}$ (2 in) thickness in a single pass. Full-depth removal involves ripping and breaking the pavement using a rhino horn on a bulldozer or pneumatic pavement breakers. In most instances, the broken material is picked up, loaded into haul trucks by a front-end loader, and transported to a central facility for processing. At this facility, the RAP is processed using a series of operations, including crushing, screening, conveying, and stacking (Pradhan \& Sahoo, 2021; Roja et al., 2020) .

The most difficult challenge in the development of a new road network is to implement projects in harmony with the concept of sustainable progress. Therefore, the road industry is looking forward to alternative materials and construction technology, an environment-friendly, energy-efficient, and costeffective way to construct and maintain road projects. Most of the current road construction practices mainly depend on naturally occurring aggregates obtained from quarries site (Belay et al., 2021; Hidalgo et al., 2020; Tarsi et al., 2020; West, 2010) . The extraction of these aggregates from their natural sources results in the loss of forest cover and pollution on a large scale leading to environmental degradation. This, in turn, has increased environmental concerns in many parts of the worldwide (Seyfe \& Geremew, 2019; Singh et al., 2020) .

The application of RAP in pavement construction has been grown rapidly in the last two decades to virgin aggregate usually used in constructing different pavement layers. Using RAP in pavement construction is considered as sustainable alternative due to its economic saving, reducing dumping of aggregate in landfills, and reducing the needs for virgin aggregate and binder. Also, the use of RAP conserve energy, lowers transportation costs required to obtain quality virgin aggregate, and preserves 
resources. For this purpose, the transportation agencies, in different parts of the world, started using high percentages of RAP in asphalt concrete mixes. 20 to $50 \%$ of RAP is typically used in HMA mixes; however, up to $80 \%$ RAP has been used in some HMA pavements (Abu Abdo, 2015). The rapid economic growth in Ethiopia from 2004 to 2015 10.9\% and gauges future prospects. In recent years, Ethiopia has dedicated three percent of GDP to road investments and investment program focuses mainly on rehabilitation, upgrading, and widening of the road (Shiferaw, 2017). Currently, large quantities of RAP aggregate remain unused in our country. The use of RAP in surface, base, and sub-base courses is not common, RAP will reduce the cost of highway construction and haul, and reduce improper use of local natural resources. One attractive option is to use RAP material in asphalt production. Therefore, this study investigates the Suitability of RAP in asphalt concrete production.

\section{MATERIALS AND METHODS USED Materials}

Non-probable purposive sampling techniques were adopted to collect materials used for conducting this research method.

* Crushed stone Aggregate ( Coarse, and Fine)

* Bitumen ( 60/70 Penetration Grade),

* Mineral Filler (Crushed Stone Dust),

* Reclaimed Asphalt Pavement Aggregate (Extracted coarse and fine).

\section{Study design}

For this research work, an experimental type design was performed as shown Figure 1. To achieve the study's objective, numerous laboratory tests were conducted to determine the Suitability of Reclaimed Asphalt Pavement Aggregate (RAPA) in Hot Mix Asphalt Production.

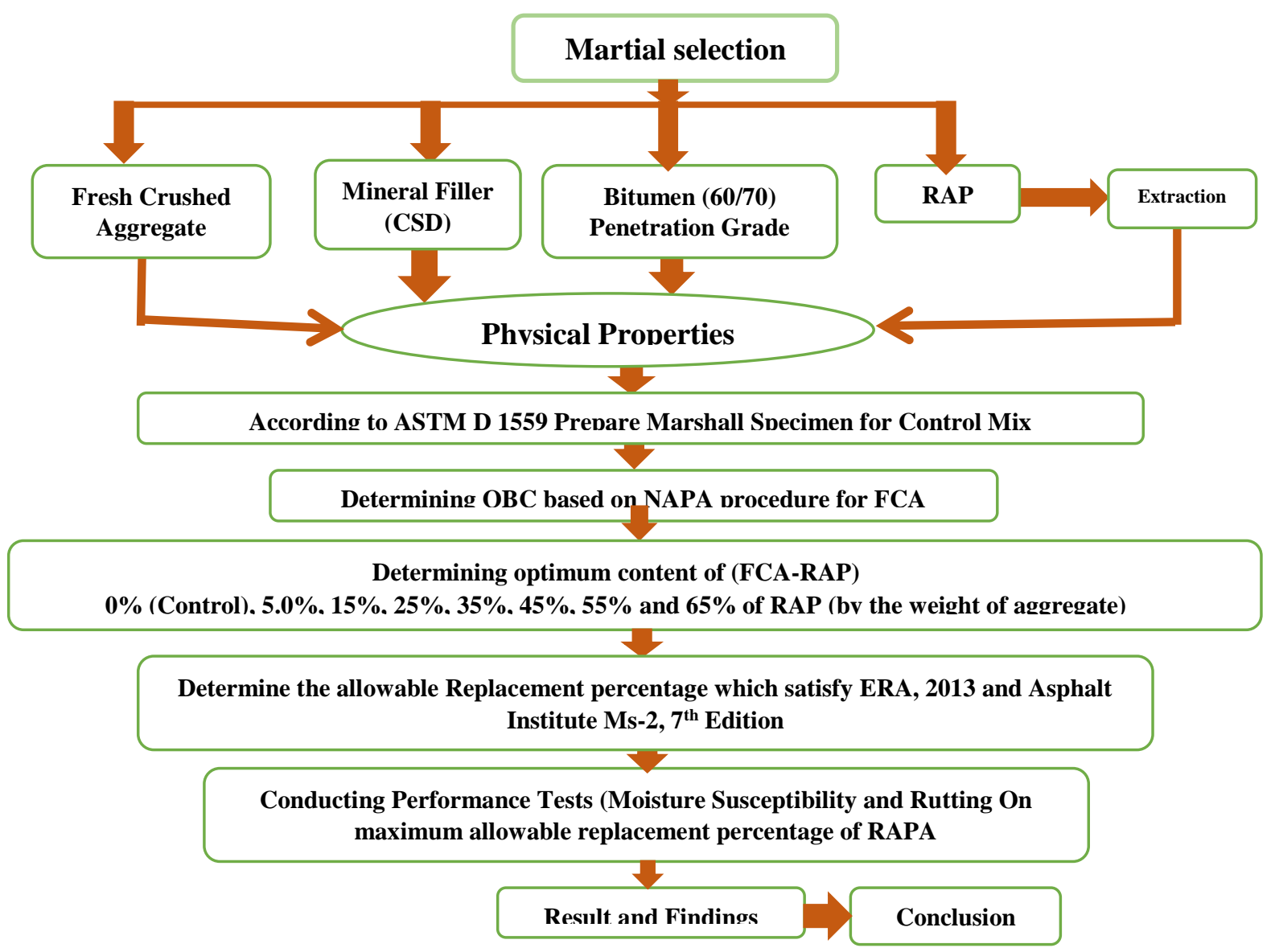


Figure 1. Research design method.

\section{Standards and Specification for this Study}

There are various test were conducted based on standard specification procedures as listed in Table 1, Table 2, Table 3 and Table 4 to determine the engineering property of the materials used for this study.

Table 1. RAPA and crushed stone aggregate (CSA) engineering quality tests and methods.

\begin{tabular}{|c|l|l|}
\hline \multicolumn{1}{|c|}{ Material } & \multicolumn{1}{|c|}{ Test conducted } & \multicolumn{1}{c|}{ Test method } \\
\hline RAP & Extraction by centrifuge method & ASTMD 2172 \\
\hline \multirow{5}{*}{$\begin{array}{c}\text { Aggregate test for } \\
\text { crushed aggregate } \\
\text { and RAPA }\end{array}$} & Los Angles abrasion value & AASHTO T-96 \\
\cline { 2 - 3 } & Aggregate crushing value & BS 812, Part 110 \\
\cline { 2 - 3 } & Aggregate impact value & BS 812, Part 112 \\
\cline { 2 - 3 } & Elongation index & BS 812, Part 105 \\
\cline { 2 - 3 } & Flakiness index & BS 812, Part 105 \\
\cline { 2 - 3 } & Specific gravity of coarse aggregate & AASHTO T 85 \\
\cline { 2 - 3 } & Specific gravity of fine aggregate & AASHTO T 84 \\
\cline { 2 - 3 } & Water absorption & BS 812, Part 2 \\
\cline { 2 - 3 } & A sieve analysis (Gradation) & AASHTO T-27 \\
\cline { 2 - 3 } & Blending & ASTMD 3515 \\
\hline
\end{tabular}

Table 2. Performed bitumen test and test methods.

\begin{tabular}{|l|l|l|}
\hline Material & \multicolumn{1}{|c|}{ Test conducted } & \multicolumn{1}{c|}{ Test method } \\
\hline \multirow{4}{*}{ Bitumen } & Penetration test & AASHTO T- 49 \\
\cline { 2 - 3 } & Specific gravity & ASTM D-70-97 \\
\cline { 2 - 3 } & Ductility & AASHTO T- 51-94 \\
\cline { 2 - 3 } & Softening point & AASHTO T- 53 \\
\cline { 2 - 3 } & Flash point & ASTM D-92 \\
\hline
\end{tabular}

Table 3. Test and test methods of mineral filler material.

\begin{tabular}{|l|c|l|}
\hline Material & Test conducted & \multicolumn{1}{|c|}{ Test method } \\
\hline \multirow{3}{*}{ Filler } & Specific gravity & ASTM D-854 \\
\cline { 2 - 3 } & Plasticity Index (PI) & ASTM D-4318 \\
\cline { 2 - 3 } & Gradation & ASTM D-242 \\
\hline
\end{tabular}

Table 4. Performance tests for control and modified mix.

\begin{tabular}{|l|l|}
\hline Test & TEST METHOD \\
\hline TSR & AASHTO T 283 \\
\hline Rutting test & AASHTO TP 63 \\
\hline
\end{tabular}

\section{RESULT AND DISCUSSION}

\section{Aggregate quality and physical property test result}

A huge quantity of reclaimed asphalt pavement is produced each year worldwide due to different reasons. These materials are produced while asphalt concrete pavements are removed during reconstruction, resurfacing, or access to buried utilities. However, there are some concerns and uncertainties about the actual environmental problem, an economic aspect and mechanical performance of asphalt mixture containing recycled aggregates. To investigate the physical properties of aggregates and their suitability in road construction, the various tests were conducted, and the test result is presented 
in Table 5. The specific gravity of aggregate was determined for each percentage replacement of RAPA in crushed aggregate with each size proportion of aggregate 9- $25 \mathrm{~mm}, 2.36-9.5 \mathrm{~mm}$, and 0$2.36 \mathrm{~mm}$, which is very important for the determination of VMA and VFA of HMA.

Table 5. Physical properties of RAPA and crushed Stone aggregate (CSA) for the study.

\begin{tabular}{|l|l|c|c|c|}
\hline \multirow{2}{*}{ Test } & \multirow{2}{*}{ Test method } & \multicolumn{2}{c|}{ Test result [\%] } & \multirow{2}{*}{ Specification } \\
\cline { 3 - 4 } & & CSA & RAPA & \\
\hline Los Angeles Abrasion (LAA), [\%] & AASHTO T- 96 & 13.67 & 14.3 & $<35 \%$ \\
\hline Aggregate Crushing Value (ACV), [\%] & BS:812, Part 110 & 13.86 & 16.67 & $<25 \%$ \\
\hline Aggregate Impact Value (AIV) [\%] & BS:812, Part 112 & 10.45 & 14.61 & $<25 \%$ \\
\hline Elongation index & BS 812, Part 105 & 11.27 & 11.43 & $<15 \%$ \\
\hline Flakiness index & BS 812,Part 105 & 23.89 & 23.07 & $<45 \%$ \\
\hline Specific gravity $>4.75$ & AASHTO T-85 & 2.831 & 2.680 & N/A \\
\hline Specific gravity $<4.75$ & AASHTO T-84 & 2.703 & 2.824 & N/A \\
\hline Water absorption of aggregate $>4.75 \mathrm{~mm}$ & BS 812,Part 2 & 1.23 & 1.48 & $<2$ \\
\hline Water absorption of aggregate $<4.75 \mathrm{~mm}$ & BS 812,Part 2 & 1.55 & 1.42 & $<2$ \\
\hline
\end{tabular}

N/A - Not Applicable

\section{Aggregate gradation for the study}

Hot mix asphalt (HMA) is graded by the percentage of different size aggregate particles it contains as shown in Figure 6. Aggregate gradation should convince the control points specified by the specification guideline for Particle Size distributions HMA production. With $19 \mathrm{~mm}$, maximum aggregate nominal size and three different percentages of fillers $5.0 \%, 5.5 \%$, and $6 \%$ by weight of total mix added to the mix aggregate gradation for the study was performed in two different parts. The first part of aggregate gradation is for the control mix, and the second gradation is gradation blended with RAPA Figure 2, Figure 3 and Figure 4 respectively. Based on the standard specification of ASTM D3515 all aggregate gradation curves were drawn and upper limit, lower limit, maximum density (middle value) and gradation trials were indicated with a different color. Consequently, the gradation trials of control and RAPA convince the standard specification requirements.

Table 6. Suggested percentage combination of stockpile aggregate.

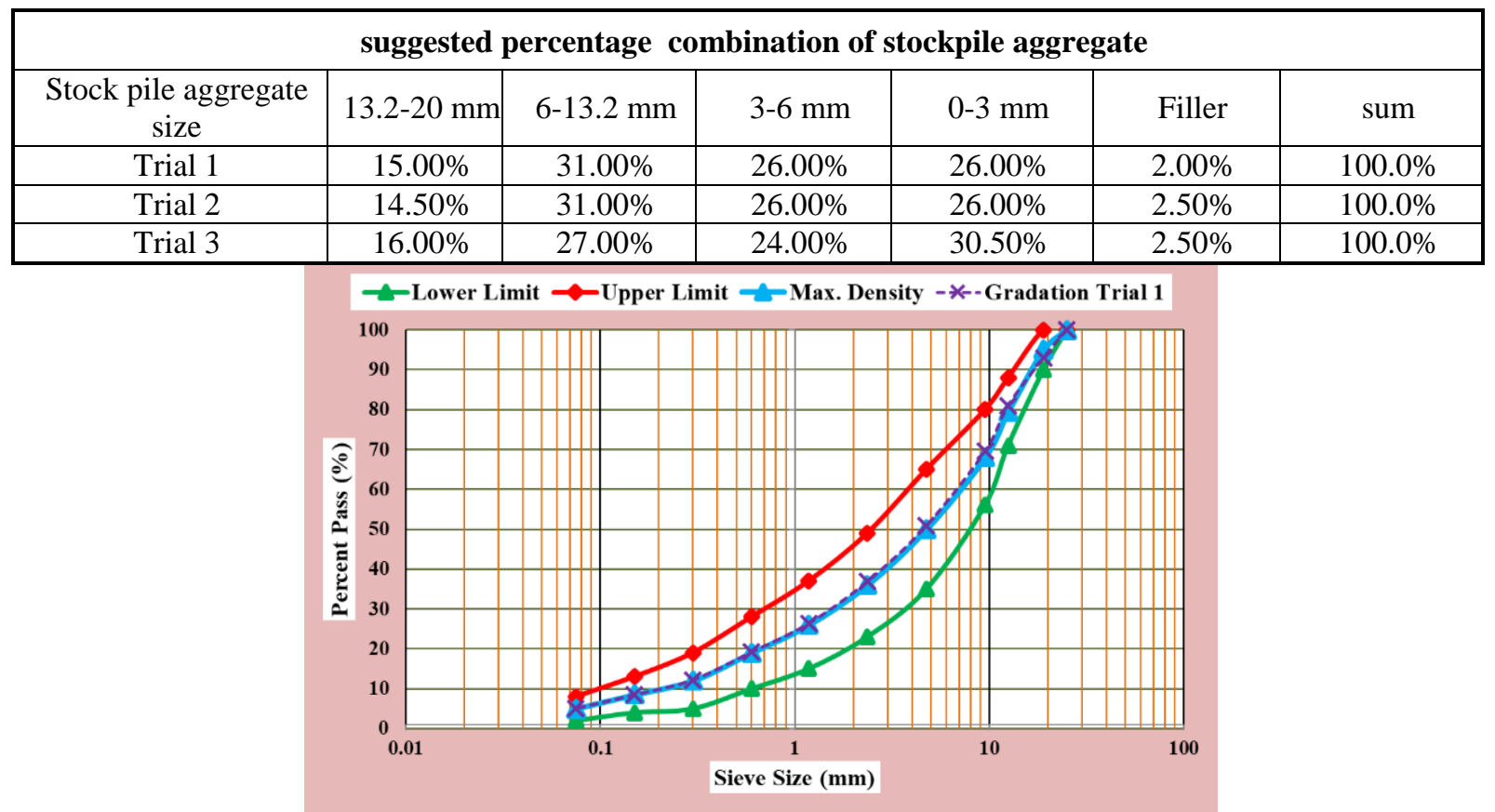

Figure 2. Aggregate gradation curve for 5.0\% mineral filler gradation. 


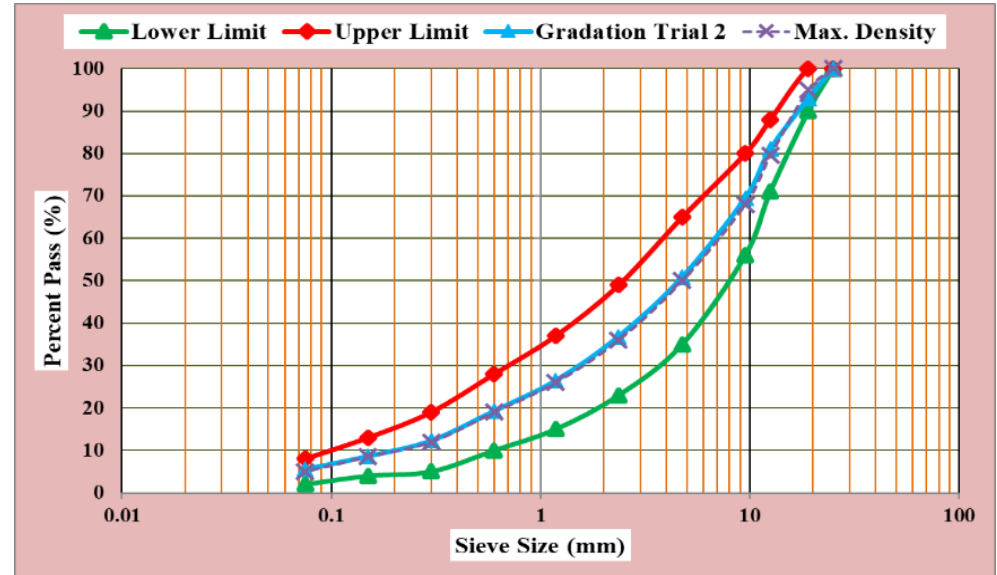

Figure 3. Aggregate gradation curve for 5.5\% mineral filler gradation.

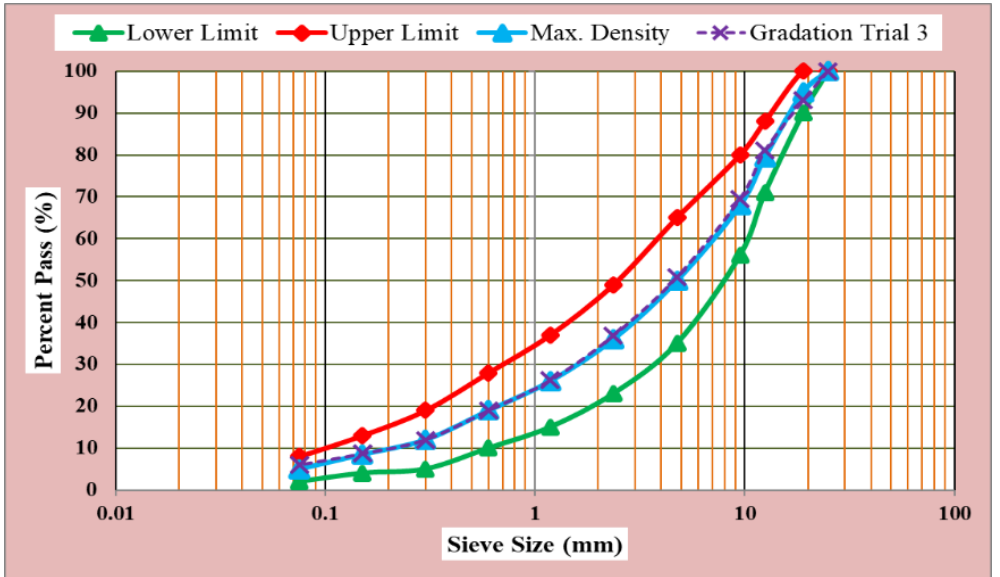

Figure 4. Aggregate gradation curve for $6.0 \%$ mineral filler gradation.

\section{Bitumen Quality Test Result}

For this study's performance, a series of bitumen quality tests were conducted as shown in Table 7 before the mix design was started.

Table 7. Physical properties of bitumen.

\begin{tabular}{|c|c|c|c|c|}
\hline Test & Unit & Test method & Result & $\begin{array}{l}\text { Recommended specification As } \\
\text { ERA for bitumen } 60 / 70\end{array}$ \\
\hline 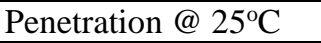 & $1 / 10 \mathrm{~mm}$ & AASHTO T 49 & 65 & $60-70$ \\
\hline Ductility@25 ${ }^{\circ} \mathrm{C}$ & $\mathrm{cm}$ & AASHTO T 51 & 108 & $\min 50$ \\
\hline Softening point & ${ }^{\circ} \mathrm{C}$ & AASHTO T 53 & 48 & $46-56$ \\
\hline Specific gravity $25^{\circ} \mathrm{C}$ & $\mathrm{kg} / \mathrm{cm}^{3}$ & ASTM D-70-97 & 1022 & --- \\
\hline Flashing point & ${ }^{\circ} \mathrm{C}$ & ASTM D-92 & 546 & $\min 232$ \\
\hline
\end{tabular}

\section{Crushed Stone Dust Mineral Filler Properties}

The laboratory tests were conducted to evaluate the physical properties of crushed rock filler as shown in Table 8, which consists of the apparent specific gravity and plasticity index according to ASTMD-854, using the water Pycnometer method.

Table 8. Physical properties of filler material used.

\begin{tabular}{|c|l|c|c|c|}
\hline S/N & \multicolumn{1}{|c|}{ Test description } & Test method & Result & $\begin{array}{c}\text { ERA Design standard } \\
\text { specification 2002 }\end{array}$ \\
\hline 1 & Apparent specific gravity $\left[\mathrm{kg} / \mathrm{m}^{3}\right]$ & ASTM D-854 & 2.848 & N/A \\
\hline 2 & Plasticity Index (PI) & ASTMD-423 & NP & $\leq 4$ \\
\hline 3 & $\%$ passing $0.6 \mathrm{~mm}$ sieve & ASTM D-242 & 100 & 100 \\
\hline 4 & $\%$ passing $0.3 \mathrm{~mm}$ sieve & ASTM D-242 & 96.5 & $95-100$ \\
\hline 5 & $\%$ passing $0.075 \mathrm{~mm}$ sieve & ASTM D-242 & 89.7 & $70-100$ \\
\hline
\end{tabular}

$\mathrm{NP}=$ Non-Plastic, N/A = Not Available 


\section{Analysis of Asphalt Mixture Properties \\ Marshall Test result of Control mix}

The control mix was prepared with three different aggregate gradation $5.0 \%, 5.5 \%$ and $6.0 \%$ mineral filler content and with five different bitumen content $4.0 \%, 4.5 \%, 5.0 \%, 5.5 \%$ and $6.0 \%$ to determine the optimum bitumen content and design gradation for the study. The control mix was used to govern the other RAPA replacement. For this study, all figures drawn to determine bitumen content were by $4^{\text {th }}$ order degree because the data points those bitumen content values are five as shown in Table 9, Table 10 and Table 11.

Table 9. Marshall Properties of asphalt mixes with $5.0 \%$ mineral filler.

\begin{tabular}{|c|c|c|c|c|c|c|}
\hline \multicolumn{7}{|c|}{ Marshall properties result 5.0\% Mineral filler by wt. aggregate } \\
\hline $\begin{array}{c}\text { Bitumen content by wt. of } \\
\text { total mix [\%] }\end{array}$ & $\begin{array}{c}\text { Air voids } \\
{[\%]}\end{array}$ & $\begin{array}{c}\text { Bulk sg. } \\
{\left[\mathrm{g} / \mathrm{cm}^{3}\right]}\end{array}$ & $\%$ VMA & $\%$ VFA & $\begin{array}{c}\text { Stability } \\
{[\mathrm{kN}]}\end{array}$ & $\begin{array}{c}\text { Flow } \\
{[\mathrm{mm}]}\end{array}$ \\
\hline 4.0 & 8.05 & 2.371 & 16.64 & 50.27 & 8.7 & 2.19 \\
\hline 4.5 & 6.37 & 2.389 & 16.44 & 60.34 & 9.7 & 2.54 \\
\hline 5.0 & 3.96 & 2.403 & 16.38 & 69.69 & 10.6 & 2.96 \\
\hline 5.5 & 2.55 & 2.413 & 16.48 & 83.34 & 10.2 & 3.48 \\
\hline 6.0 & 1.71 & 2.421 & 16.65 & 90.84 & 9.2 & 3.84 \\
\hline
\end{tabular}

The relationships between bitumen content and the mixture properties such as air voids, bulk specific gravity, VMA, VFA, stability and flow by Marshall Method. As air void is decreasing with increased bitumen content, the value of stability and the unit weight the total mix (bulk density) increases with increasing bitumen content up to pick a point and then gradually decrease although the increase in bitumen content. The value of voids filled with asphalt VFA and flow increases with an increase of bitumen content. In contrast, the percent of voids in mineral aggregate VMA decreases minimum value and increases as bitumen content increases. According to the NAPA mix design method criteria, the mix to have $4.0 \%$ air voids at optimum bitumen content. Using this procedure, the optimum bitumen content was found to be $4.94 \%$ (by weight of the total mix). The laboratory test result of the mixture with an aggregate gradation of trial 2 was 5.5\% mineral filler and the corresponding values of Marshall Properties for control mix as shown in Table 10.

Table 10. Marshall Properties of asphalt mixes with $5.5 \%$ mineral filler.

\begin{tabular}{|c|c|c|c|c|c|c|}
\hline \multicolumn{7}{|c|}{ Marshall properties result 5.5\% mineral filler by wt. aggregate } \\
\hline $\begin{array}{c}\text { Bitumen content by wt. of } \\
\text { total mix [\%] }\end{array}$ & $\begin{array}{c}\text { Air voids } \\
{[\%]}\end{array}$ & $\begin{array}{c}\text { Bulk sg. } \\
{\left[\mathrm{g} / \mathrm{cm}^{3}\right]}\end{array}$ & $\%$ VMA & $\%$ VFA & $\begin{array}{c}\text { Stability } \\
{[\mathrm{kN}]}\end{array}$ & $\begin{array}{c}\text { Flow } \\
{[\mathrm{mm})}\end{array}$ \\
\hline 4.0 & 7.25 & 2.374 & 16.51 & 53.96 & 9.2 & 2.29 \\
\hline 4.5 & 5.72 & 2.389 & 16.43 & 62.60 & 10.6 & 2.70 \\
\hline 5.0 & 4.14 & 2.402 & 16.40 & 70.04 & 11.3 & 3.09 \\
\hline 5.5 & 3.21 & 2.414 & 16.44 & 79.83 & 10.5 & 3.42 \\
\hline 6.0 & 2.56 & 2.424 & 16.53 & 84.51 & 9.5 & 3.68 \\
\hline
\end{tabular}

It relationship between bitumen content and mixture properties with aggregate gradation $5.5 \%$ mineral filler. The mix's optimum bitumen content that resulted in $4.0 \%$ air voids of the specification is $5.10 \%$ from the figure shown below. The over-all curve correlation between bitumen content and the Marshall properties for $5.5 \%$ mineral filler is similar to $5.0 \%$ mineral filler. Table 11 shows the obtained laboratory test result of the Marshall properties of the mix at different bitumen content with aggregate gradation with $6.0 \%$ mineral filler content.

Table 11. Marshall Properties of asphalt mixes with $6.0 \%$ mineral filler

\begin{tabular}{|c|c|c|c|c|c|c|}
\hline \multicolumn{7}{|c|}{ Marshall properties result 6.0\% mineral filler by wt. aggregate } \\
\hline $\begin{array}{c}\text { Bitumen content by wt. of } \\
\text { total mix [\%] }\end{array}$ & $\begin{array}{c}\text { Air voids } \\
{[\%]}\end{array}$ & $\begin{array}{c}\text { Bulk sg. } \\
{\left[\mathrm{g} / \mathrm{cm}^{3}\right]}\end{array}$ & $\%$ VMA & \% VFA & $\begin{array}{c}\text { Stability } \\
{[\mathrm{kN}]}\end{array}$ & $\begin{array}{c}\text { Flow } \\
{[\mathrm{mm}]}\end{array}$ \\
\hline 4.0 & 7.10 & 2.373 & 16.57 & 57.15 & 9.7 & 2.39 \\
\hline 4.5 & 5.89 & 2.388 & 16.45 & 64.17 & 10.8 & 2.90 \\
\hline 5.0 & 4.70 & 2.402 & 16.40 & 71.32 & 11.2 & 3.32 \\
\hline 5.5 & 3.41 & 2.413 & 16.48 & 78.68 & 10.6 & 3.69 \\
\hline
\end{tabular}




\begin{tabular}{|l|l|l|l|l|l|l|}
6.0 & 2.54 & 2.423 & 16.57 & 84.69 & 9.4 & 3.85 \\
\hline
\end{tabular}

The relationship between bitumen content and mixture properties with aggregate gradation 5.5\% mineral filler. The optimum bitumen content of the mix that resulted in $4.0 \%$ air voids of the specification is $5.28 \%$. The over-all curve correlation between bitumen content and the Marshall properties for $6.0 \%$ mineral filler is similar to 5.0 and $5.5 \%$ mineral filler.

\section{Determination of Optimum bitumen Content for Control mix (0\% RAPA)}

The optimum bitumen content for the control mix with three different aggregate gradations contains $5.0 \%, 5.5 \%$ and $6.0 \%$ mineral filler was determined by using the Marshall test (ASTM D1559) and one of the methods called the National Asphalt Pavement Association (NAPA). According to the procedure that was suggested that the optimum bitumen content (OBC) was determined by finding the bitumen content, which corresponds to the median air void $4.0 \%$ of the specification. This bitumen content Marshall Stability, Flow, VFA, VMA, and bulk specific gravity was determined. Depending on the result, the optimum bitumen content at $4.0 \%$ air voids is $4.94 \%, 5.1 \%$, and $5.28 \%$ by weight of total mix for the respective $5.0 \%, 5.5 \%$, and $6.0 \%$ crushed stone mineral filler. Table 12 summarizes the bitumen content corresponding to the standard specification criteria. The Marshall stability of a mixture of trial $1(5.0 \%$ mineral filler content), trial 2 (5.5\% mineral filler content), and trial 3 (6.0\% mineral filler content) aggregate gradations were $10.3,11.42$, and $10.92 \mathrm{KN}$, respectively. It indicates that $5.5 \%$ mineral filler has maximum stability than the other two aggregate gradation trials. So that, $5.5 \%$ and $5.1 \%$ were selected as the optimum mineral filler content and optimum bitumen content, respectively.

Therefore these results, OBC and corresponding to other Marshall properties of this mix gradation, were used as control mix and for RAP replacement, moisture susceptibility and rutting test evaluation.

Table 12. Comparison of Marshall Properties of asphalt mixes with 5\%, 5.5\% and 6\% mineral filler with the specification.

\begin{tabular}{|c|c|c|c|c|c|c|c|c|}
\hline \multirow{2}{*}{ Marshall properties } & \multicolumn{3}{|c|}{ Marshall result of control mix } & \multicolumn{2}{|c|}{$\begin{array}{l}\text { ERA } 2002 \\
\text { specification limit }\end{array}$} & \multicolumn{2}{|c|}{$\begin{array}{c}\text { Asphalt institute } \\
\text { limits }\end{array}$} & \multirow[b]{2}{*}{ Status } \\
\hline & $\begin{array}{l}\text { Trail 1 } \\
{[5.0 \%]}\end{array}$ & $\begin{array}{l}\text { Trail } 2 \\
{[5.5 \%]}\end{array}$ & Trail 3 [6.0\%] & Lower & Upper & Lower & Upper & \\
\hline Optimum bitumen [\%] & 4.94 & 5.10 & 5.28 & 4 & 10 & 4 & 10 & $\mathrm{Ok}$ \\
\hline Stability $[\mathrm{kN}]$ & 10.51 & 11.42 & 10.92 & $\min 7$ & - & $\min 8.006$ & - & $\mathrm{Ok}$ \\
\hline Flow value $[\mathrm{mm}]$ & 2.86 & 3.10 & 3.49 & 2 & 4 & 2 & 3.5 & Ok \\
\hline VMA [\%] & 16.37 & 16.41 & 16.42 & $\min 13$ & - & - & - & Ok \\
\hline VFA [\%] & 67.54 & 71.6 & 74.98 & 65 & 75 & 65 & 75 & Ok \\
\hline Air Void [\%] & 4.00 & 4.00 & 4.00 & 3 & 5 & 3 & 5 & Ok \\
\hline $\begin{array}{l}\text { Bulk specific gravity } \\
{\left[\mathrm{g} / \mathrm{cm}^{3}\right]}\end{array}$ & 2.400 & 2.404 & 2.406 & - & - & - & - & - \\
\hline
\end{tabular}

Marshall Test Result of RAPA Replacement of Crushed Aggregate

The Marshall Test results of mixture properties mixed with $5.0 \%$ RAPA and $95 \%$ crushed aggregate is illustrated in Table 13. Marshall Properties of the mix at different bitumen content with aggregate gradation with $5.5 \%$ mineral filler content. The replacement RAPA in place of fresh crushed aggregate was performed based on selected design gradation of the control mix which is trial 2 that presented in Table 10.

Table 13. Marshall Properties of asphalt mixes with 5.5\% mineral filler and 5.0\% RAPA replacement.

\begin{tabular}{|c|c|c|c|c|c|c|}
\hline \multicolumn{7}{|c|}{ Marshall properties result 5.5\% CSD and 5\% RAPA by wt. aggregate } \\
\hline $\begin{array}{c}\text { Bitumen content by wt. of } \\
\text { total mix [\%] }\end{array}$ & $\begin{array}{c}\text { Air voids } \\
{[\%]}\end{array}$ & $\begin{array}{c}\text { Bulk sg. } \\
{\left[\mathrm{g} / \mathrm{cm}^{3}\right]}\end{array}$ & $\%$ VMA & $\%$ VFA & $\begin{array}{c}\text { Stability } \\
{[\mathrm{kN}]}\end{array}$ & $\begin{array}{c}\text { Flow } \\
{[\mathrm{mm}]}\end{array}$ \\
\hline 4.0 & 6.69 & 2.372 & 16.59 & 53.97 & 8.5 & 2.33 \\
\hline 4.5 & 5.26 & 2.388 & 16.45 & 62.61 & 9.9 & 2.75 \\
\hline 5.0 & 4.01 & 2.404 & 16.36 & 70.08 & 11.0 & 3.12 \\
\hline 5.5 & 2.98 & 2.413 & 16.47 & 79.85 & 9.8 & 3.48 \\
\hline
\end{tabular}


6.0

2.00

2.423

16.58

84.52

8.2

3.71

The relationships between optimum bitumen content and mix properties contain 5\% RAPA and 95\% CSA. The relationships between bitumen content and the mixture properties such as air voids, bulk specific gravity, VMA, VFA stability and flow curves are plotted. The optimum bitumen content was found equal to 5.04 by weight of the total mix. Table 14 presented the Marshall Test results of mixture properties mixed with 15\% RAPA and $85 \%$ fresh Crushed Aggregate. Marshall Properties of the mix at different bitumen content with aggregate gradation with 5.5\% mineral filler content was performed based on selected design gradation of control mix which is trial 2 that presented in Table 10.

Table 14. Marshall Properties of asphalt mixes with 5.5\% mineral filler and 15\% RAPA replacement.

\begin{tabular}{|c|c|c|c|c|c|c|}
\hline \multicolumn{6}{|c|}{ Marshall properties result 5.5\% CSD and 15\% RAPA by wt. aggregate } \\
\hline $\begin{array}{c}\text { Bitumen content by wt. of } \\
\text { total mix [\%] }\end{array}$ & $\begin{array}{c}\text { Air voids } \\
{[\%]}\end{array}$ & $\begin{array}{c}\text { Bulk sg. } \\
{\left[\mathrm{g} / \mathrm{m}^{3}\right]}\end{array}$ & $\%$ VMA & $\%$ VFA & $\begin{array}{c}\text { Stability } \\
{[\mathrm{kN}]}\end{array}$ & $\begin{array}{c}\text { Flow } \\
{[\mathrm{mm}]}\end{array}$ \\
\hline 4.0 & 6.70 & 2.360 & 16.20 & 58.63 & 8.3 & 2.36 \\
\hline 4.5 & 5.23 & 2.383 & 15.94 & 66.73 & 9.4 & 2.85 \\
\hline 5.0 & 3.79 & 2.400 & 15.73 & 73.67 & 10.2 & 3.26 \\
\hline 5.5 & 2.70 & 2.406 & 15.88 & 82.77 & 9.8 & 3.56 \\
\hline 6.0 & 1.72 & 2.412 & 16.13 & 89.32 & 8.6 & 3.78 \\
\hline
\end{tabular}

The optimum bitumen content and mix properties contain $15 \%$ RAPA and $85 \%$ FCA. At $5.0 \%$, the relationships between bitumen content and the mixture properties such as air voids, bulk specific gravity, VMA, VFA stability and flow curves are plotted. The optimum bitumen content was found equal to 4.98 by weight of the total mix. Table 15 presented the Marshall test results of mixture properties mixed with $25 \%$ RAPA and $75 \%$ fresh crushed aggregate. Marshall Properties of the mix at different bitumen content with aggregate gradation with $5.5 \%$ mineral filler content. As the RAPA replacement in $5.0 \%$ and $15 \%$ RAP aggregate in place of crushed aggregate was performed based on selected design gradation of control mix which is trial 2 that presented in Table 10.

Table 15. Marshall Properties of asphalt mixes with 5.5\% mineral filler and 25\% RAPA replacement.

\begin{tabular}{|c|c|c|c|c|c|c|}
\hline \multicolumn{6}{|c|}{ Marshall properties result 5.5\% CSD and 25\% RAPA by wt. aggregate } \\
\hline $\begin{array}{c}\text { Bitumen content by wt. of } \\
\text { total mix [\%] }\end{array}$ & $\begin{array}{c}\text { Air voids } \\
{[\%]}\end{array}$ & $\begin{array}{c}\text { Bulk sg. } \\
{\left[\mathrm{g} / \mathrm{m}^{3}\right]}\end{array}$ & $\%$ VMA & $\%$ VFA & $\begin{array}{c}\text { Stability } \\
{[\mathrm{kN}]}\end{array}$ & $\begin{array}{c}\text { Flow } \\
{[\mathrm{mm}]}\end{array}$ \\
\hline 4.0 & 6.53 & 2.362 & 16.11 & 59.46 & 8.1 & 2.40 \\
\hline 4.5 & 5.01 & 2.382 & 15.83 & 67.29 & 9.2 & 2.83 \\
\hline 5.0 & 3.63 & 2.399 & 15.70 & 74.93 & 9.8 & 3.28 \\
\hline 5.5 & 2.48 & 2.408 & 15.82 & 83.71 & 9.7 & 3.56 \\
\hline 6.0 & 1.48 & 2.415 & 16.03 & 90.77 & 8.4 & 3.79 \\
\hline
\end{tabular}

The relationships between optimum bitumen content and mix properties contain $25 \%$ RAPA and $75 \%$ CSA and its optimum bitumen content was found equal to $4.87 \%$ by weight of the total mix. Table 16 presented the Marshall Test results of mixture properties mixed with 35\% RAPA and $65 \%$ crushed aggregate. Marshall Properties of the mix at different bitumen content with aggregate gradation with 5.5\% mineral filler content. All properties and gradation are performed as 5.0\%, $15 \%$ and $25 \%$.

Table 16. Marshall Properties of asphalt mixes with 5.5\% mineral filler and 35\% RAPA replacement.

\begin{tabular}{|c|c|c|c|c|c|c|}
\hline \multicolumn{6}{|c|}{ Marshall properties result 5.5\% CSD and 35\% RAPA by wt. aggregate } \\
\hline $\begin{array}{c}\text { Bitumen content by } \\
\text { wt. of total mix [\%] }\end{array}$ & $\begin{array}{c}\text { Air voids } \\
{[\%]}\end{array}$ & $\begin{array}{c}\text { Bulk sg. } \\
{\left[\mathrm{g} / \mathrm{m}^{3}\right]}\end{array}$ & $\%$ VMA & $\%$ VFA & $\begin{array}{c}\text { Stability } \\
{[\mathrm{kN}]}\end{array}$ & $\begin{array}{c}\text { Flow } \\
{[\mathrm{mm}]}\end{array}$ \\
\hline 4.0 & 6.55 & 2.359 & 16.23 & 59.65 & 7.7 & 2.44 \\
\hline 4.5 & 4.92 & 2.381 & 15.89 & 68.60 & 8.4 & 2.95 \\
\hline 5.0 & 3.45 & 2.402 & 15.57 & 76.91 & 9.0 & 3.40 \\
\hline 5.5 & 2.22 & 2.410 & 15.73 & 85.92 & 8.8 & 3.67 \\
\hline 6.0 & 1.44 & 2.415 & 16.02 & 91.02 & 7.8 & 3.85 \\
\hline
\end{tabular}

The relationships between optimum bitumen content and mix properties contain 35\% RAPA and 75\% CSA. The relationships between bitumen content and the mixture properties such as air voids, bulk specific gravity, VMA, VFA stability and flow curves are also plotted as done before. The optimum 
bitumen content was found equal to $4.81 \%$ by weight of the total mix. Table 17 presented the Marshall test results of mixture properties mixed with 45\% RAPA and 55\% fresh crushed aggregate. Marshall Properties of the mix at different bitumen content with aggregate gradation with $5.5 \%$ mineral filler content was performed.

Table 17. Marshall Properties of asphalt mixes with 5.5\% mineral filler and 45\% RAPA replacement.

\begin{tabular}{|c|c|c|c|c|c|c|}
\hline \multicolumn{6}{|c|}{ Marshall properties result 5.5\% CSD and 45\% RAPA by wt. aggregate } \\
\hline $\begin{array}{c}\text { Bitumen content by wt. of } \\
\text { total mix [\%] }\end{array}$ & $\begin{array}{c}\text { Air voids } \\
{[\%]}\end{array}$ & $\begin{array}{c}\text { Bulk sg. } \\
{\left[\mathrm{g} / \mathrm{m}^{3}\right]}\end{array}$ & $\%$ VMA & $\%$ VFA & $\begin{array}{c}\text { Stability } \\
{[\mathrm{kN}]}\end{array}$ & $\begin{array}{c}\text { Flow } \\
{[\mathrm{mm}]}\end{array}$ \\
\hline 4.0 & 6.18 & 2.364 & 16.03 & 61.46 & 7.0 & 2.49 \\
\hline 4.5 & 4.72 & 2.381 & 15.76 & 69.65 & 7.9 & 3.13 \\
\hline 5.0 & 3.19 & 2.396 & 15.55 & 78.43 & 8.1 & 3.60 \\
\hline 5.5 & 2.02 & 2.410 & 15.73 & 87.20 & 7.5 & 3.89 \\
\hline 6.0 & 1.38 & 2.415 & 16.01 & 91.40 & 6.7 & 4.07 \\
\hline
\end{tabular}

The relationships between optimum bitumen content and mix properties contain $45 \%$ RAPA and $55 \%$ CSA. The optimum bitumen content was found equal to $4.74 \%$ by weight of the total mix. Table 18 presented the Marshall Test results of mixture properties mixed with 45\% RAPA and 55\% crushed aggregate. Marshall Properties of the mix at different bitumen content with aggregate gradation with 5.5\% mineral filler content. All Marshall Properties and gradation was used here were the same as used for bitumen content $5.0 \%, 15 \%, 25 \%, 35 \%$ and $45 \%$.

Table 18. Marshall Properties of asphalt mixes with 5.5\% mineral filler and 55\% RAPA replacement.

\begin{tabular}{|c|c|c|c|c|c|c|}
\hline \multicolumn{6}{|c|}{ Marshall properties result 5.5\% CSD and 55\% RAPA by wt. aggregate } \\
\hline $\begin{array}{c}\text { Bitumen content by wt. of } \\
\text { total mix [\%] }\end{array}$ & $\begin{array}{c}\text { Air voids } \\
{[\%]}\end{array}$ & $\begin{array}{c}\text { Bulk sg. } \\
{\left[\mathrm{g} / \mathrm{m}^{3}\right]}\end{array}$ & $\%$ VMA & $\%$ VFA & $\begin{array}{c}\text { Stability } \\
{[\mathrm{kN}]}\end{array}$ & $\begin{array}{c}\text { Flow } \\
{[\mathrm{mm}]}\end{array}$ \\
\hline 4.0 & 6.08 & 2.365 & 16.01 & 61.48 & 5.7 & 2.92 \\
\hline 4.5 & 4.47 & 2.377 & 15.60 & 70.09 & 6.6 & 3.49 \\
\hline 5.0 & 2.80 & 2.394 & 15.33 & 81.60 & 6.8 & 3.83 \\
\hline 5.5 & 1.67 & 2.406 & 15.54 & 89.20 & 6.6 & 4.01 \\
\hline 6.0 & 1.21 & 2.418 & 15.90 & 92.40 & 5.8 & 4.19 \\
\hline
\end{tabular}

The relationships between optimum bitumen content and mix properties contain 55\% RAPA and $45 \%$ FCA. The relationships between bitumen content and the mixture properties such as air voids, bulk specific gravity, VMA, VFA stability and flow curves plotted the same as for bitumen content 5\%, 15\%, $25 \%, 35 \%$ and $45 \%$. The optimum bitumen content was found equal to 4.67 by weight of the total mix. Table 19 presented the Marshall Test results of mixture properties mixed with $65 \%$ RAPA and $35 \%$ crushed aggregate. Marshall Properties of the mix at different bitumen content with aggregate gradation with 5.5\% mineral filler content. All things here were also done as 5\%, 15\%, 25\%, 35\%, 45\% and 55\%.

Table 19. Marshall Properties of asphalt mixes with 5.5\% mineral filler and 65\% RAPA replacement.

\begin{tabular}{|c|c|c|c|c|c|c|}
\hline \multicolumn{7}{|c|}{ Marshall properties result 5.5\% CSD and 55\% RAPA by wt. aggregate } \\
\hline $\begin{array}{c}\text { Bitumen content by wt. of } \\
\text { total mix [\%] }\end{array}$ & $\begin{array}{c}\text { Air voids } \\
{[\%]}\end{array}$ & $\begin{array}{c}\text { Bulk sg. } \\
{\left[\mathrm{g} / \mathrm{m}^{3}\right]}\end{array}$ & $\%$ VMA & $\%$ VFA & $\begin{array}{c}\text { Stability } \\
{[\mathrm{kN}]}\end{array}$ & Flow [mm] \\
\hline 4.0 & 5.84 & 2.369 & 15.86 & 63.17 & 5.7 & 2.92 \\
\hline 4.5 & 4.85 & 2.376 & 15.66 & 69.06 & 6.6 & 3.49 \\
\hline 5.0 & 3.10 & 2.400 & 15.26 & 79.71 & 6.8 & 3.83 \\
\hline 5.5 & 1.59 & 2.416 & 15.54 & 89.78 & 6.6 & 4.01 \\
\hline 6.0 & 1.23 & 2.416 & 15.98 & 92.34 & 5.8 & 4.19 \\
\hline
\end{tabular}

The relationships between optimum bitumen content and mix properties contain 65\% RAPA and $35 \% \mathrm{CSA}$ and the optimum bitumen content was found equal to 4.53 by weight of the total mix. This trial was done to be sure that the next replacement was not recommended.

\section{OBC determination for each RAP Aggregate Proportion with CA}

The optimum bitumen content for each RAPA Proportion is determined according to NAPA (National Asphalt Pavement Association, The bitumen content corresponds to the specification's 
median air void content (4 percent typically) of the specification. This is the optimum bitumen content. The bitumen content is then used to determine the value for Marshall Stability, VMA, flow, bulk density, and percent voids filled from each of the plots. Compare each of these values against the specification values for that property, and if all are within the specification range, the bitumen content at 4 percent air voids is optimum bitumen content. If any of these properties are outside the specification range, the mixture should be redesigned. Table 20 presented the Marshall Test results of mixture properties with a $5.5 \%$ mineral filler and different RAPA contents. The comparison with the standard specification is also illustrated, except 55\% and 65\% of all replacements satisfied for ERA 2002 and Asphalt institute manuals.

Table 20. Summary of Marshall Properties for control and replacement

\begin{tabular}{|c|c|c|c|c|c|c|c|c|c|c|c|c|}
\hline \multirow{2}{*}{$\begin{array}{l}\text { Marshall } \\
\text { properties }\end{array}$} & \multicolumn{8}{|c|}{ Marshall result of control mix and replacement } & \multicolumn{2}{|c|}{$\begin{array}{c}\text { ERA } 2002 \\
\text { specification limit }\end{array}$} & \multicolumn{2}{|c|}{$\begin{array}{l}\text { Asphalt institute } \\
\text { limits }\end{array}$} \\
\hline & 0 & 5 & 15 & 25 & 35 & 45 & 55 & 65 & Lower & Upper & Lower & Upper \\
\hline $\begin{array}{l}\text { Optimum } \\
\text { bitumen [\%] }\end{array}$ & 5.10 & 5.04 & 4.98 & 4.87 & 4.81 & 4.74 & 4.67 & 4.53 & 4 & 10 & 4 & 10 \\
\hline Stability $[\mathrm{kN}]$ & 11.42 & 10.98 & 10.45 & 9.74 & 8.98 & 8.11 & 6.70 & 6.10 & $\min 7$ & -- & $\min 8.006$ & \\
\hline Flow $[\mathrm{mm}]$ & 2.86 & 3.10 & 3.14 & 3.19 & 3.25 & 3.31 & 3.45 & 3.51 & 2 & 4 & 2 & 3.5 \\
\hline VMA [\%] & 16.41 & 16.37 & 15.80 & 15.69 & 15.61 & 15.54 & 15.48 & 15.40 & $\min 13$ & -- & -- & \\
\hline VFA [\%] & 71.60 & 71.90 & 72.60 & 73.25 & 74.00 & 74.68 & 74.87 & 75.36 & 65 & 75 & 65 & 75 \\
\hline Air Void [\%] & 4.0 & 4.0 & 4.0 & 4.0 & 4.0 & 4.0 & 4.0 & 4.0 & 3 & 5 & 3 & 5 \\
\hline $\begin{array}{l}\text { Bulk specific } \\
\text { gravity }\left[\mathrm{g} / \mathrm{cm}^{3}\right]\end{array}$ & 2.404 & 2.401 & 2.399 & 2.395 & 2.392 & 2.388 & 2.383 & 2.379 & - & - & - & - \\
\hline status & OK & OK & OK & OK & OK & OK & $\begin{array}{c}\text { Not } \\
\text { satisfied. }\end{array}$ & $\begin{array}{c}\text { Not } \\
\text { satisfied. }\end{array}$ & & & & \\
\hline
\end{tabular}

\section{Discussion and Analysis of Marshall Test results at optimum bitumen content}

After the Marshall properties of asphalt mixture mixed with different percentages of RAP aggregate at each optimum bitumen content were determined, the next step was to evaluate RAP aggregate's potential effect on Marshall Properties. Since the objective of the study was to determine the effect of RAP aggregate on Marshall Properties, it is important to evaluate how the Marshall properties were changed by the addition of recycled percentage in the asphalt mix. The effect of RAP aggregate on Marshall Properties was evaluated based Control mix of the study and standard specification. Using the conventional mix's Marshall Properties, we can evaluate the other Marshall Properties results mixed with different RAP aggregate percentages. Furthermore, the value of Marshall Properties obtained at each OBC mixed with different RAPA percentages compared to the ERA design standard specification to evaluate the effects and determine the maximum RAP aggregate used in hot mix asphalt (HMA). Based on Marshall Properties result at each of optimum bitumen content mixed with different percentage of RAP aggregate presented in Table 18.

\section{Effect of RAPA on Bitumen content}

The experimental results in Table 20 and Figure 5, the value of optimum bitumen content mixed with $0 \%$ RAPA aggregate (control mix) is greater than the other mixes 5\%, 15\%, 25\%, 35\%, 45\%, 55\% and $65 \%$ RAP aggregate. From this, it can be noticed that the optimum bitumen content is decreased as Reclaimed Asphalt Pavement RAP aggregate is increased. This is due to the old bitumen, filled the pore of the RAP aggregate. Moreover, increasing RAP from zero to 65\% decrease the optimum bitumen content from 5.1 to $4.74 \%$. This means that saving in optimum bitumen content by about $7.05 \%$ is achieved. But the bitumen might be old, so it is not considered as a high benefit. 


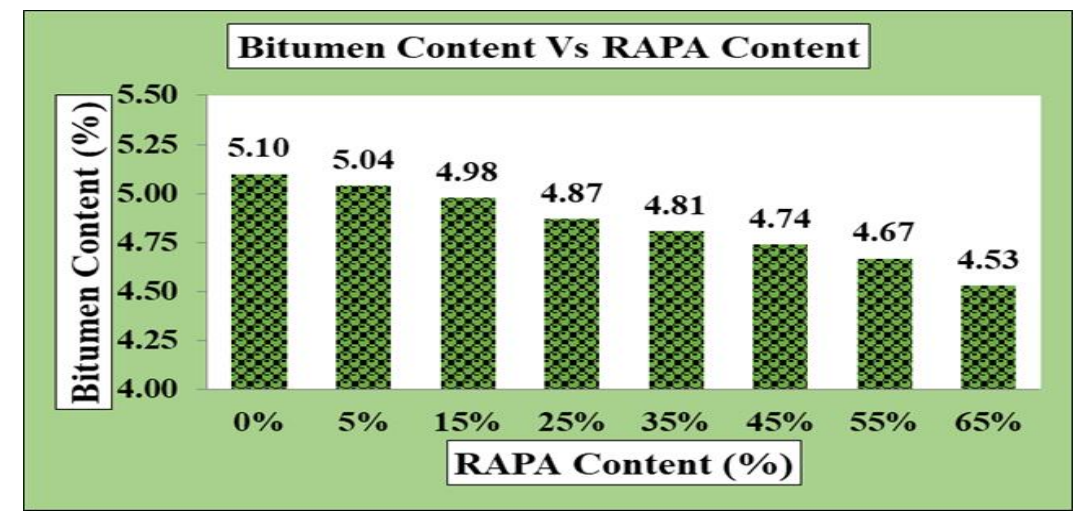

Figure 5. Comparison of Bitumen Content result at each RAPA percentage.

\section{Effect of RAPA on Bulk specific gravity}

RAPA has an unpronounced effect on the bulk density and its result with different RAPA percentage is presented in Table 11 and Figure 6; from this result, it was noticed that the value of Bulk density is decreased up to 65\% RAPA replacement. This may be due to the Aggregate's bulk specific gravity, which means the bulk specific gravity of aggregate decreases.

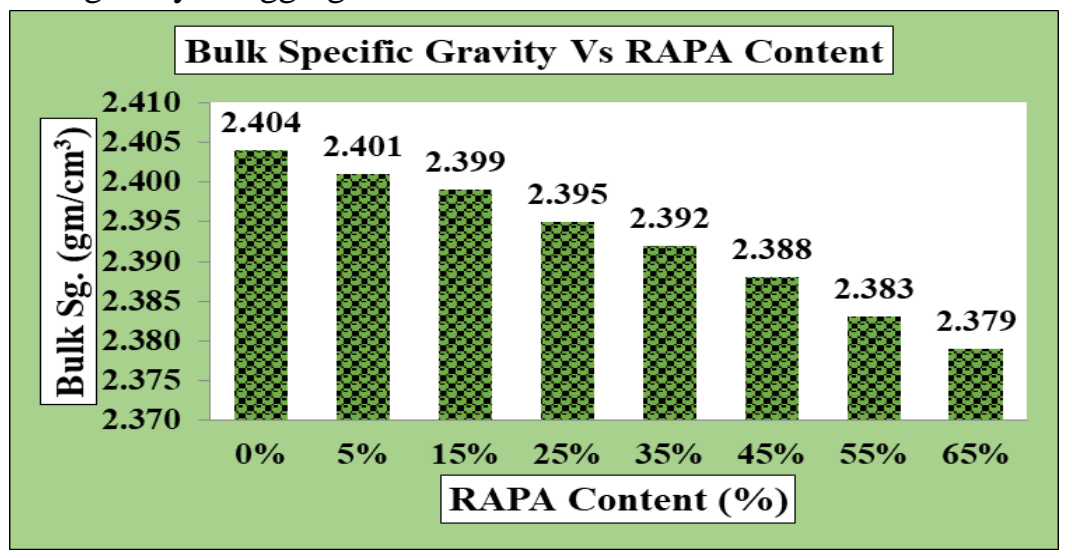

Figure 6. Comparison of bulk specific gravity result at each RAPA percentage.

\section{Effect of RAPA on the void in mineral aggregate}

Void in mineral Aggregate is the volume of intergranular void space between the aggregate particles of a compacted paving mixture, including air voids and bitumen volume not absorbed by aggregate. The mix's durability increases with thin layer thickness on the aggregate particles, and minimum requirements for VMA are recommending getting a more durable pavement structure. VMA value at OBC presented in Table 18 and Figure 7 was used to evaluate RAP aggregate effect on VMA. As we see in (Figure16) the VMA mix value is greater in 0\% RAPA (control mix) and decreased to RAPA replacement of up to $65 \%$. This shows that the Void in mineral aggregate is decreased with the increase in both bitumen content and RAP percentage in the mixture. This may is due to the Recycled aggregate and bitumen is perfectly blended with virgin materials and fills the space between compacted materials. 


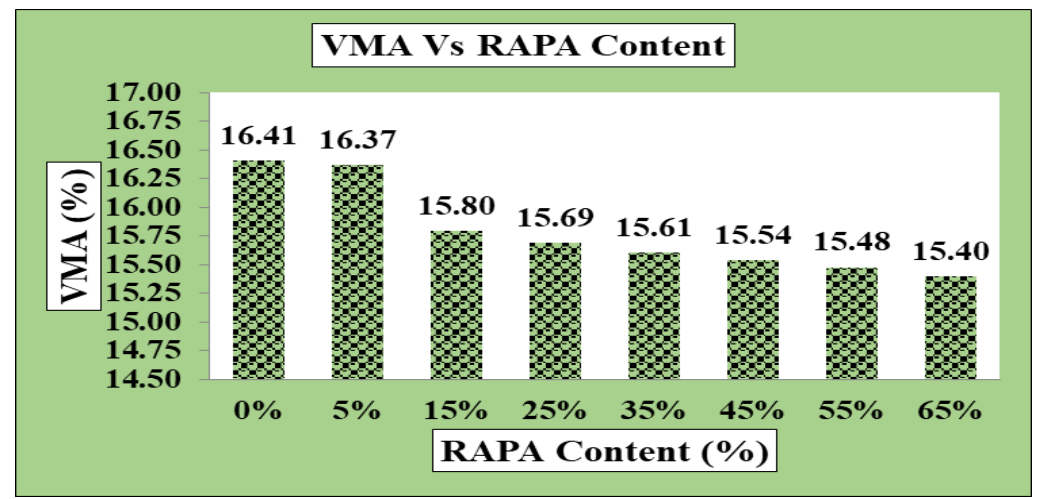

Figure 7. Comparison of VMA result at each RAPA percentage.

\section{Effect of RAPA on void filled with asphalt}

The VFA represents the volume of the effective bitumen content and ensures that the effective asphalt part of the VMA in a mix is not too little or too great and helps avoid those mixes subject to rutting in heavy traffic situations. The value of VFA at optimum bitumen content was present in Table 20 and Figure 8 identify that the VFA the result of the conventional mix (0\% RAP) was small rather than the VFA value mixed up to $65 \%$ RAPA replacement. Generally, this shows that VFA value increases as RAPA in the mix increased ease due to old bitumen in the replaced aggregate.

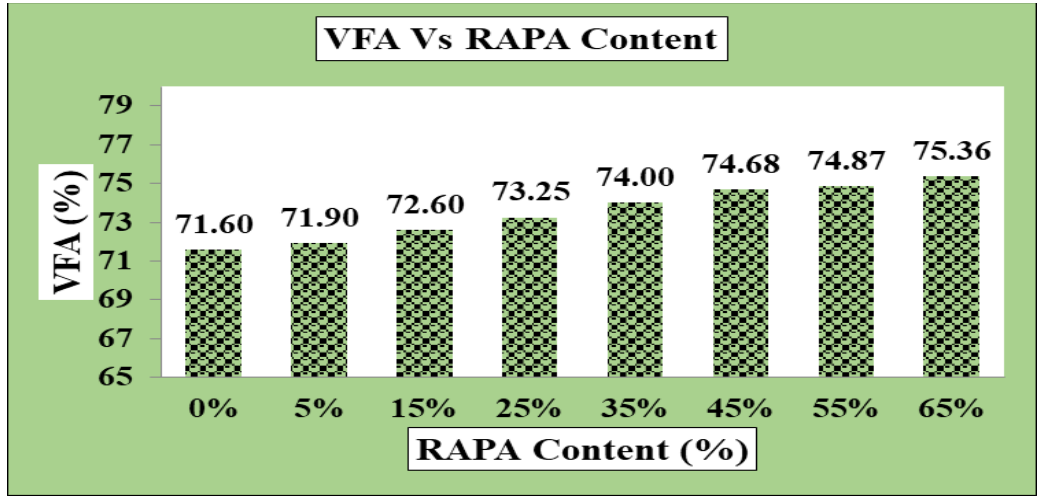

Figure 8. Comparison of VFA result at each RAPA percentage.

\section{Effect of RAPA in stability}

Marshall Stability is the most important parameter to know the maximum load resistance that the specimen will achieve at $60^{\circ} \mathrm{C}$ under specified conditions in the asphalt mix design. Stability is always related to the aggregate gradation; the coarse aggregate gradation in the mix has higher stability rather than fine aggregate gradation. The result of stability at Optimum bitumen content is presented in Table 20 and Figure 9 to determine the potential effect of RAPA on Marshall Stability. From Figure 19 we have obtained that the value of stability at $0 \%$ RAPA (control mix) is greater than the value of stability mixed with the different percentage of RAPA. The value of stability decreases gradually up to $45 \%$ RAPA replacement, and after that, it becomes out of the range. This may be due to the Recycled aggregate is used material and loaded before, so it becomes finer than the virgin aggregate, which has less stability than the coarse aggregate. 


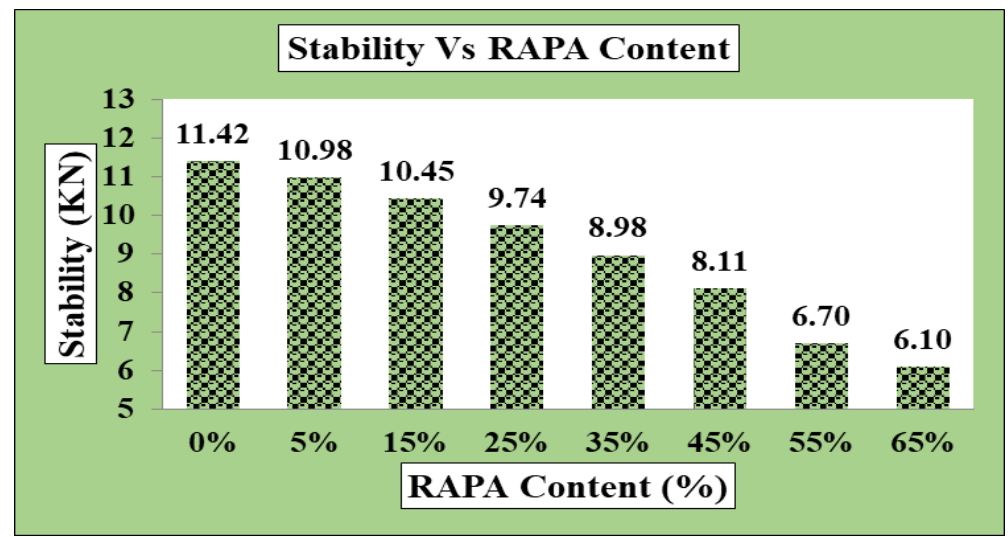

Figure 9. Comparison of stability result at each RAPA percentage.

\section{Effect of RAPA on a flow}

Flow in hot mix asphalt is an indicator of resistance to permanent vertical deformation. High flow values indicate that the mix contains a high amount of asphalt binder that fills all voids and affects the resistance to permanent deformation under traffic; in contrast, low flow values may indicate a mix has higher voids and insufficient asphalt binder, so it causes a crack mixture to become brittle. From Figure 10 we have seen that the value of Marshall Flow increases as the percentage of RAP aggregate increases. We see that the flow result mixed with $0 \%$ RAP aggregate has a minimum value rather than RAPA replacement up to $65 \%$ from the value presented. When the RAP aggregate increases from zero to $65 \%$, the mix flow value is increased but in the range of specifications. Here we see that the RAP aggregate content in hot mix asphalt can affect the value of Marshall Flow.

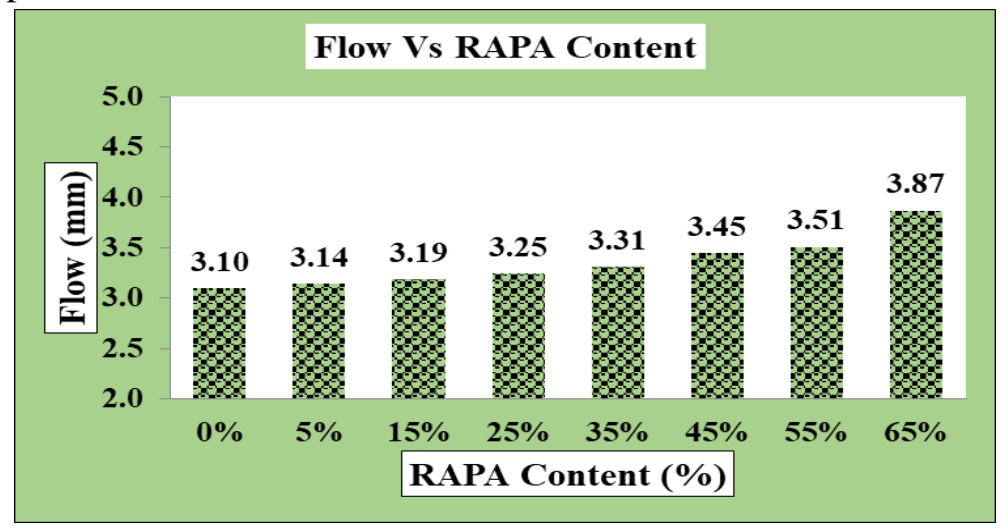

Figure 10. Comparison of flow result at each RAPA percentage.

\section{Performance tests}

\section{Effects of RAP on Moisture Susceptibility of HMA}

The Moisture damage of HMA is evaluated based on by comparing the mixes of several properties before moisture cases of conditioning and after it. Tensile strength ratio (TSR) is used to predict the moisture susceptibility of the mixtures. In this study, a total of 42 samples were prepared with a varying percentage of RAP $0 \%$ (Control mix) 5\%, 15\%, 25\%, 35\%, and 45\% by weight of aggregate using optimum bitumen content of each replacement.

\section{Indirect Tensile Strength}

The dry and wet conditioned specimens were subjected to indirect tensile strength, and the result obtained for both cases were averaged. Table 21 indicates the results obtained from the indirect tensile strength (ITS) test. 
Table 21. Summary indirect tensile strength test results

\begin{tabular}{|c|c|c|c|c|}
\hline \multirow{2}{*}{$\begin{array}{c}\text { RAPA content } \\
{[\%]}\end{array}$} & \multirow{2}{*}{$\begin{array}{c}\text { OBC } \\
{[\%]}\end{array}$} & \multicolumn{2}{|c|}{ Indirect tensile strength [kPa] } & \multirow{2}{*}{ TSR [\%] } \\
\cline { 3 - 4 } & & Unconditioned & Conditioned & \\
\hline $0 \%$ & 5.10 & 760.0 & 699.6 & 92.05 \\
\hline $5 \%$ & 5.04 & 750.9 & 684.5 & 91.16 \\
\hline $15 \%$ & 4.98 & 717.8 & 646.2 & 90.03 \\
\hline $25 \%$ & 4.87 & 708.2 & 625.1 & 88.27 \\
\hline $35 \%$ & 4.81 & 695.7 & 604.1 & 86.83 \\
\hline $45 \%$ & 4.74 & 673.7 & 575.5 & 85.42 \\
\hline
\end{tabular}

As in Figure 11 shows the indirect tensile strength (ITS) test result for control mix and mixes containing RAP. The laboratory results of indirect tensile strength of conditioned samples have different values as compared to unconditioned specimens. As observed in the figure below the values of indirect tensile strength of the two cases increase with an increase RAP until the optimum replacement proportion $55 \%$, and it has a higher value of the control mix. The obtained results of the control sample (0\%RAP) and mix prepared with replacement proportion RAP, i.e. $5 \%, 15 \%, 25 \%, 35 \%$, and $45 \%$, both for the unconditioned, and conditioned or wet sample were $760 \mathrm{kPa}, 750.9 \mathrm{kPa}, 717.8 \mathrm{kPa}, 708.2 \mathrm{kPa}, 695.7 \mathrm{kPa}$, and $673.7 \mathrm{kPa}$, and $699.6 \mathrm{kPa}, 684.5 \mathrm{kPa}, 646.2 \mathrm{kPa} 625.1 \mathrm{kPa}, 604.1 \mathrm{kPa}$, and $575.5 \mathrm{kPa}$ respectively.

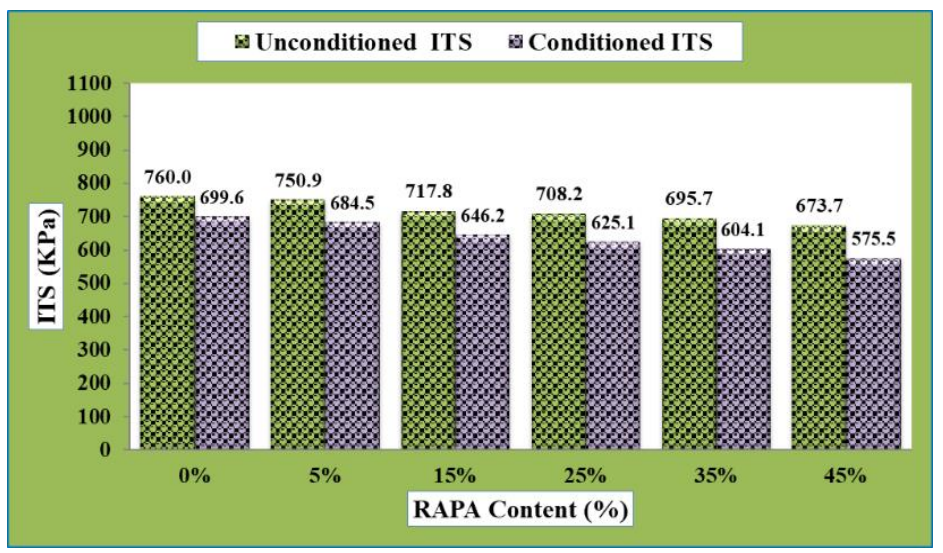

Figure 11. Unconditioned and conditioned ITS of HMA with varying percentage of RAPA.

\section{Tensile Strength Ratios (TSR)}

In Figure 12 shows the tensile strength ratio for both control and RAP mixtures of HMA. As displayed in the graph below, the TSR values decrease with increasing RAPA content. The highest TSR value is $92.06 \mathrm{kPa}$ at the control mix and the minimum TSR value is $85.42 \mathrm{KPa}$ at $45 \%$ RAPA content in the mix. Therefore, it can be said that RAPA mix is highly susceptible to moisture damage compared to mixes containing control mix and the moisture damage rises with the increasing of RAPA content. But, all the mixes have the potential to resist moisture damage since the TSR values obtained are greater than the recommended specification $80 \%$. 


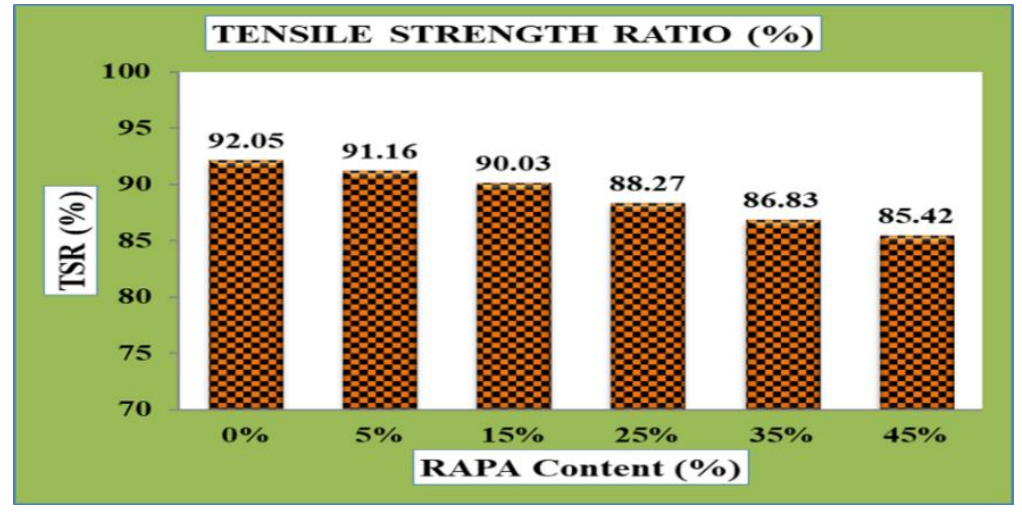

Figure 12. Tensile strength ratio (TSR) of HMA mixture containing RAPA.

\section{Rutting test}

The most basic element in the performance of asphalt is its resistance to rutting. It causes the loss of road surface regularity, which evidently has a negative impact on the quality of service to users. Resistance to rutting the wheel tracking test was performed for both control and the highest allowable RAPA replacement mixes. Figure 13 illustrated the laboratory test result for both control mixes. 100\% FCR or control mix had a better rutting resistance performance than mix blend with recycled asphalt pavement aggregate. Figure 13 illustrates rut depth with respect to the number of passes. The comparison showed that the rutting that occurred in the samples blended mix with recycled asphalt pavement aggregate at temperatures $60^{\circ} \mathrm{C}$ is less than that of control mix or fresh crushed aggregate. But the result was almost the same average rutting depth. The figure also showed the rate of deformation decrease as the depth of rutting increases.

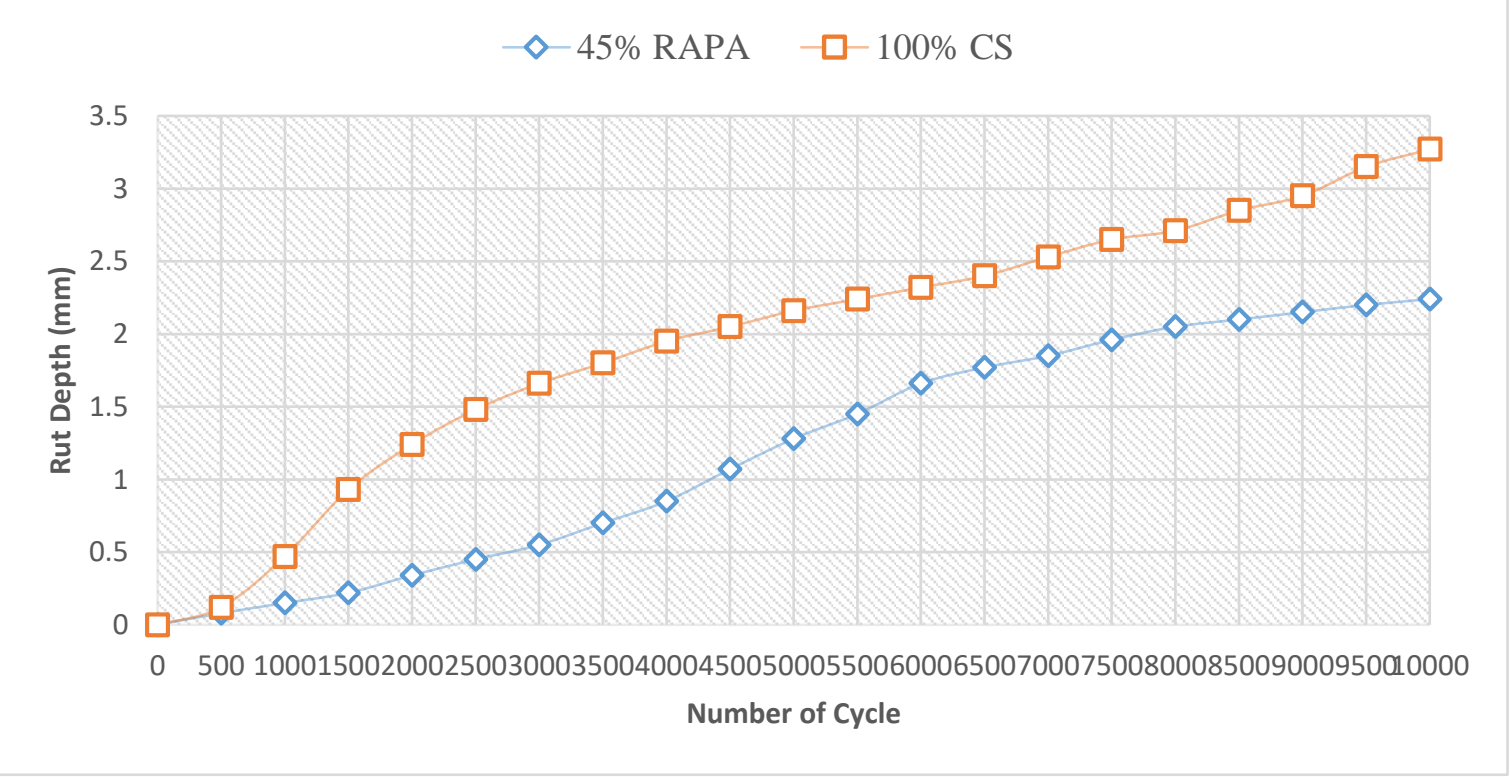

Figure 13. Wheel Tracking Test results for conventional and RAPA replacement.

\section{Comparison of rutting result with specifications}

In Table 22 showed the result of conventional or control mix and modified mix satisfy the requirement. It showed that recycled asphalt pavement aggregate replaces up to $45 \%$ of fresh crushed aggregate by the weight of aggregate that is used in the control mix.

Table 22: Comparison rutting performance of asphalt mix control and RAPA with standard specification.

\begin{tabular}{|c|c|c|c|c|}
\hline \multicolumn{5}{|c|}{ Results of the UNE-EN 12697- 22 wheel-tracking test } \\
\hline \multirow{2}{*}{ Mix name } & $\begin{array}{c}\text { WTS }_{\text {AIR }} \\
\text { PRD [\%] }\end{array}$ & \multirow{2}{*}{ Mean RD } & Specification as per \\
\cline { 3 - 5 } & $=((\mathrm{d} 10000-\mathrm{RD} 5000) / 500 / \mathrm{h}) / 2))$ & EN 13108 \\
\hline
\end{tabular}




\begin{tabular}{|c|c|c|c|c|c|}
\hline & $\left(\mathrm{mm} / 10^{3}\right.$ load cycles $)$ & & {$[\mathrm{mm}]$} & & \\
& & & & PRD [\%] & RD [mm] \\
\hline 100\%CA & 0.222 & 6.540 & 3.270 & $<9$ & $<6.5$ \\
\hline 55\%CA\&45\%RAPA & 0.192 & 4.480 & 2.240 & $<9$ & $<6.5$ \\
\hline
\end{tabular}

\section{Determination of Maximum percentage of using RAPA in HMA}

Depending on the physical property of materials, Marshall Stability results and the performance testes moisture susceptibility and rutting compression of Marshall Properties with based on the standard specification was determined based on the maximum RAPA percentage. The maximum amount of RAPA in hot mix asphalt is replaced up to $45 \%$ only; i.e.; 45\% RAPA mixed with Fresh crushed aggregate satisfies the required standard specification range, which illustrated in ERA, Pavement Design Manual, 2013 and Asphalt institute Ms-2, Sixth Edition.

\section{CONCLUSIONS}

Based on this experimental study for the following conclusion were made, the engineering properties of selected materials in this study such as aggregates (extracted RAP and CSA), filler and bitumen laboratory tests were conducted based on standard test procedures of ASTM, AASHTO and BS. This materials satisfies the specification of quality test specified by Asphalt institute standard specification and Ethiopian road authority; consequently, RAPA can be used in HMA production based on the pretest that conducted and satisfies specification. In order to determine the optimum bitumen content three different aggregate gradation size which contains $5 \%, 5.5 \%$ and $6 \%$ mineral filler with five different amounts of bitumen content $4 \%, 4.5 \%, 5.0 \%, 5.5 \%$, and $6.0 \%$ by weight of the total mix was prepared. Therefore, aggregate gradation containing a $5.5 \%$ mineral filler has maximum stability, with $5.1 \%$ of optimum bitumen content of $5.0 \%$ among the three aggregate gradations. To determine RAPAs optimum bitumen content to each replacement percentage $5 \%, 15 \%, 25 \%, 35 \%, 45 \%, 55 \%$ and $65 \%$ with five different bitumen content $4 \%, 4.5 \%, 5 \%, 5.5 \%$ and $6 \%$ by weight of total mix have done by using NAPA method and determine each Marshall and volumetric properties stability and flow. Consequently, except 55\% and $65 \%$, all replacements were under standard specification. At 45\% RAPA with $4.74 \%$ optimum bitumen content replacement of fresh crushed aggregate, the mixture properties such as Marshall Stability, flow values and volumetric properties are satisfied with the ERA Pavement Design Manual and asphalt institute specification limits. Tensile Strength Ratio value decreased as the RAPA content increased, but highly satisfied the standard specification, and the mix provides resistance to moisture-induced damage. Rutting depth is also permitted in EN standard specification, so that this mix design provides resistance to deformation. The obtained value of Tensile Strength Ratio, proportional rut depth and mean rut depth on $45 \%$ RAPA replacement was $85.42 \%$ and $4.48 \%, 2.24 \mathrm{~mm}$ respectively. As a whole, based on laboratory studies it was concluded that a maximum of $45 \%$ RAPA can be as crushed aggregate in the hot mix asphalt.

\section{RECOMMENDATIONS}

Pavement construction, maintenance, and rehabilitation are increasing in Ethiopia; hence 95\% of hot mix asphalt is aggregate. An endeavor to work on replacing construction materials to be done by road authorities and any other concerned bodies. The Reclaimed Asphalt Pavement aggregate (RAPA) is recommended to use in hot mix asphalt mixes instead of pure crushed aggregate with minimum bitumen content to save the natural resource. RAP aggregate content is changing the value of volumetric parameters, so it is important to know the relationship between those two variables (RAPA and CA) during Asphalt mix design. A percent of RAPA up to 45 is suitable to be used in flexible pavement construction during hot mix production for the study. 


\section{REFERENCES}

Abu Abdo, A. M. 2015. Utilizing Reclaimed Asphalt Pavement (RAP) Materials in New Pavements-A Review. International Journal of Thermal and Environmental Engineering, 12(1). https://doi.org/10.5383/ijtee.12.01.008

Alwetaishi, M., Kamel, M., \& Al-Bustami, N. 2019. Sustainable applications of asphalt mixes with reclaimed asphalt pavement (RAP) materials: Innovative and new building brick. International Journal of Low-Carbon Technologies, 14(3), 364-374. https://doi.org/10.1093/ijlct/ctz023

Belay, S., Quezon, E. T., \& Geremew, A. 2021. Effect of Selected Conventional and Non-conventional Mineral Fillers with 'Enset' Fibers on Compaction Characteristics of Stone Mastic Asphalt Pavement (SMAP). Jordan Journal of Civil Engineering, 15(1), 11.

Geraldin, J., \& Makmur, A. 2020. Experimental Study on the Effects of Reclaimed Asphalt Pavement towards Marshall Parameters on Asphalt Course-Wearing Course. IOP Conference Series: Earth and Environmental Science, 498, 012025. https://doi.org/10.1088/1755-1315/498/1/012025

Gonfa, L. G., Tucay Quezon, E. T. Q., \& Geremew, A. 2020. EXPERIMENTAL STUDY ON APPLICATION OF MARBLE WASTE AS CONVENTIONAL AGGREGATE FOR BASE COURSE MATERIALS. Journal of Civil Engineering, Science and Technology, 11(2), 144-163. https://doi.org/10.33736/jcest.2620.2020

Hidalgo, A. E., Moreno-Navarro, F., Tauste, R., \& Rubio-Gámez, M. C. 2020. The Influence of Reclaimed Asphalt Pavement on the Mechanical Performance of Bituminous Mixtures. An Analysis at the Mortar Scale. Sustainability, 12(20), 8343. https://doi.org/10.3390/su12208343

Hrůza, P., Blahuta, J., Pelikán, P., Olišarová, L., Nedorost, J., Mikita, T., \& Patočka, Z. 2020. Recycled Asphalt as an Alternative to Natural Aggregates for Forest Road Reinforcement. Croatian Journal of Forest Engineering, 41(1), 149-161. https://doi.org/10.5552/crojfe.2020.571

Pourtahmasb, M. S., \& Karim, M. R. 2014. Utilization of Recycled Concrete Aggregates in Stone Mastic Asphalt Mixtures. Advances in Materials Science and Engineering, 2014, 1-9. https://doi.org/10.1155/2014/902307

Pradhan, S. K., \& Sahoo, U. C. 2021. Evaluation of recycled asphalt mixtures rejuvenated with Madhuca longifolia (Mahua) oil. International Journal of Pavement Research and Technology, 14(1), 43-53. https://doi.org/10.1007/s42947-020-0279-6

Pranav, S., Aggarwal, S., Yang, E.-H., Sarkar, A. K., Singh, A. P., \& Lahoti, M. 2020. Alternative materials for wearing course of concrete pavements: A critical review. Construction and Building Materials, 236, 117609.

Roja, K. L., Masad, E., \& Mogawer, W. 2020. Performance and blending evaluation of asphalt mixtures containing reclaimed asphalt pavement. Road Materials and Pavement Design, 1-17. https://doi.org/10.1080/14680629.2020.1764858

Schaefer, V. R., Stevens, L., White, D., \& Ceylan, H. 2008. Design Guide for Subgrades and Subbases (p. 134) [Final Report]. Iowa Highway Research Board (IHRB Project TR-525).

Seyfe, M., \& Geremew, A. 2019. POTENTIAL USE OF CINDER GRAVEL AS AN ALTERNATIVE BASE COURSE MATERIAL THROUGH BLENDING WITH CRUSHED STONE AGGREGATE AND CEMENT TREATMENT. Journal of Civil Engineering, Science and Technology, 10(2), 101-112. https://doi.org/10.33736/jcest.1465.2019

Shiferaw, A. 2017. Productive Capacity and Economic Growth in Ethiopia. 1-24.

Singh, A. K., Kulshreshtha, A., Banerjee, A., \& Singh, B. R., 2020. Nanotechnology in road construction. 050002. https://doi.org/10.1063/5.0000772

Swiertz, D., Mahmoud, E., \& Bahia, H. U. 2011. Estimating the Effect of Recycled Asphalt Pavements and Asphalt Shingles on Fresh Binder, Low-Temperature Properties without Extraction and 
Recovery. Transportation Research Record: Journal of the Transportation Research Board, 2208(1), 48-55. https://doi.org/10.3141/2208-07

Tarsi, G. Tataranni, P., \& Sangiorgi, C., 2020. The Challenges of Using Reclaimed Asphalt Pavement for New Asphalt Mixtures: A Review. Materials, 13(18), 4052. https://doi.org/10.3390/ma13184052

West, R. C. 2010. RECLAIMED ASPHALT PAVEMENT MANAGEMENT: BEST PRACTICES (NCAT Report XX-XX; p. 34). National Center for Asphalt Technology at AUBURN UNIVERSITY. 